\title{
Strategi Pemecahan Masalah Heuristik: Sebuah Metode untuk Merepresentasikan Masalah Matematika dalam Pembelajaran Matematika
}

\author{
Mutia $^{1}$, Dete Konggoro \\ ${ }^{1}$ Institut Agama Islam Negeri Curup \\ ${ }^{1}$ mutia@iaincurup.ac.id
}

\begin{tabular}{|c|c|}
\hline Article Info & Abstract \\
\hline $\begin{array}{l}\text { Article history: } \\
\text { Received Nov } 11^{\text {th }} 2021 \\
\text { Revised Nov } 23^{\text {th }} 2021 \\
\text { Accepted Nov } 28^{\text {th }} 2021\end{array}$ & $\begin{array}{l}\text { In mathematics, there are two criteria for questions or } \\
\text { problems, namely challenging and demanding } \\
\text { procedures that are not routine in solving them. The } \\
\text { problem is a situation where a person is able to realize } \\
\text { the existence of a situation and admit that the situation }\end{array}$ \\
\hline $\begin{array}{l}\text { Keywords: } \\
\text { Problems; } \\
\text { Heuristik; } \\
\text { Representation }\end{array}$ & $\begin{array}{l}\text { problem solving strategies, students can make a } \\
\text { mathematical representation of the problem, which is } \\
\text { one of the abilities in mathematics related to problem } \\
\text { solving, reasoning, proof, and communication. } \\
\text { Conversely, if we choose the right representation, it will } \\
\text { allow us to reach an effective solution to the problem. } \\
\text { Heuristic is a strategy used to find and solve a } \\
\text { mathematical problem using solving steps. There are } \\
\text { many types of heuristic strategies that can be used in } \\
\text { learning mathematics to solve problems, but in this } \\
\text { study, will be discussed strategies by Mathlin, namely } \\
\text { The Analogy Approach, The Means-Ends Heuristic, and } \\
\text { The Hill-Climbing Heuristic. }\end{array}$ \\
\hline $\begin{array}{l}\text { Kata Kunci: } \\
\text { Masalah; } \\
\text { Heuristik; } \\
\text { Representasi }\end{array}$ & $\begin{array}{l}\text { Abstrak } \\
\text { Dalam matematika, ada dua kriteria pertanyaan atau } \\
\text { masalah, yaitu prosedur yang menantang dan menuntut } \\
\text { yang tidak rutin dalam menyelesaikannya. Masalah } \\
\text { adalah suatu keadaan dimana seseorang mampu } \\
\text { menyadari adanya suatu keadaan dan mengakui bahwa } \\
\text { keadaan tersebut memerlukan tindakan dan } \\
\text { penyelesaian yang tidak mudah. Dengan menggunakan } \\
\text { strategi pemecahan masalah, peserta didik selanjutnya } \\
\text { dapat membuat representasi matematis dari masalah, } \\
\text { yang merupakan salah satu kemampuan dalam } \\
\text { matematika yang berkaitan dengan pemecahan masalah, }\end{array}$ \\
\hline
\end{tabular}


penalaran, pembuktian, dan komunikasi. Sebaliknya, jika kita memilih representasi yang tepat, itu akan memungkinkan kita untuk mencapai solusi yang efektif untuk masalah tersebut. Heuristik adalah strategi yang digunakan untuk menemukan dan memecahkan masalah matematika dengan menggunakan langkah-langkah penyelesaian. Ada banyak jenis strategi heuristik yang dapat digunakan dalam pembelajaran matematika untuk memecahkan masalah, namun dalam penelitian ini akan dibahas strategi oleh Mathlin yaitu The Analogy Approach, The Means-Ends Heuristik, dan The HillClimbing Heuristik.

\section{PENDAHULUAN}

Masalah merupakan bagian yang tidak dapat dipisahkan dari kehidupan manusia. Setiap manusia pasti mengalami masalah dalam hidupnya. Jika masalah tidak diselesaikan dengan cara yang benar, maka masalah dapat menjadi kendala bagi kemajuan seseorang dan setiap orang memiliki cara yang berbeda-beda dalam menyelesaikan masalah tersebut. Suatu ketika dihadapkan dengan masalah, kita dapat menggunakan bermacam-macam strategi untuk menyelesaikannya. Strategi tertentu memang menghabiskan waktu. Namun, dengan strategi tersebut kita dapat menyelesaikan dan menemukan solusi dari sebuah masalah.

Masalah merupakan suatu situasi dimana seseorang tersebut mampu menyadari keberadaan situasi dan mengakui bahwa situasi tersebut memerlukan tindakan dan penyelesaian yang tidak mudah. Masalah juga merupakan suatu keadaan yang menunjukkan kesenjangan antara harapan dan kenyataan yang terjadi. Situasi yang menjadi masalah bagi seseorang belum tentu menjadi masalah bagi orang lain. Adapun masalah dalam matematika biasanya dalam bentuk pertanyaan atau soal. Dalam matematika terdapat dua kriteria pertanyaan atau soal yaitu bersifat menantang dan menuntut prosedur yang tidak rutin dalam penyelesaiannya (Wahyudi, 2017). Misalnya, peserta didik diberikan pertanyaan sebagai berikut: 
1. Berapa hasil penjumlahan dari $12+32$ ? dan

2. Tentukan dua bilangan bulat positif, yang jika dijumlahkan hasilnya 44 !

Manakah yang merupakan masalah matematika? Tentunya kita akan menjawab pertanyaan/soal nomor 2 merupakan masalah matematika. Mengapa? Sebab pertanyaan nomor 2 merupakan pertanyaan yang menantang dan menuntut langkah-langkah yang tidak seperti biasanya serta peserta didik dapat menjawab pertanyaan tersebut lebih dari satu jawaban. Inilah yang kemudian perlu diperhatikan oleh seorang pengajar ketika memberikan masalah matematika kepada peserta didiknya yaitu mengarahkan peserta didik untuk memikirkan langkah-langkah dan beberapa alternatif penyelesaian dari masalah tersebut supaya kreativitas mereka terbangun dalam menyelesaikan masalah yang dalam konteks ini dapat kita sebut sebagai strategi pemecahan masalah.

Melalui strategi pemecahan masalah tersebut, peserta didik dapat melakukan representasi matematis terhadap masalah yang merupakan salah satu kemampuan dalam matematika yang berkaitan dengan pemecahan masalah, penalaran, pembuktian, dan komunikasi. Sebaliknya, jika kita memilih representasi yang tepat, maka akan memungkinkan kita dapat mencapai solusi yang efektif untuk masalah tersebut. Representasi masalah mengacu pada cara menerjemahkan elemen masalah ke dalam format yang berbeda (Mathlin, Margareth W., 1994). Hal ini senada dengan pendapat yang menyatakan bahwa "learning a new procedure or strategy can change children's subsequent representation of the problem itself" (Alibali and Colleagues, 2009). Para ahli pun dalam perkembangannya juga telah mengemukakan bahwa antara strategi dan representasi memiliki dua arah dimana strategi dapat mempengaruhi representasi dari masalah, terdapat efek kausal dari penggunaan strategi ini (James A. Dixon, 2009). Kemampuan representasi sangat penting dimiliki oleh peserta didik sebagai upaya memberikan pemahaman serta gambaran dalam mengkomunikasikan penyelesaian atas masalah yang diberikan dalam pembelajaran (Wardono, 2019). Caglayan \& Olive, 2010; Goldin \& Beilock, 2010; Villegas, Castro, \& Gutiérrez, 2009; Putri \& Zulkardi, 2018; Saleh, et al. 2018 menyatakan bahwa mathematical 
representation means expressing a mathematical concept in various ways, such as languages, symbols, pictures, diagrams, models, graphs, or physical objects (Juniati, 2018). Samsudin (2018) juga menyatakan bahwa mathematical entities can be represented in multiple ways (A. F. Samsuddin, H. Retnawati, 2018). Misalnya, angka delapan dapat diwakili oleh kumpulan objek yang nyata yang ada di dalam kehidupan sehari-hari seperti delapan buah kotak, delapan buah buku, dan lain sebagainya. Selain itu, angka delapan juga dapat diwakili menggunakan gambar yaitu delapan buah kotak yang kemudian digambarkan kotak sebanyak delapan buah dan dapat juga menyatakan delapan dengan simbolik yaitu angka 8 atau VIII (jika Romawi).

Secara umum representasi matematis terdiri dari dua bagian yang tidak dapat dipisahkan, yaitu: (1) representasi eksternal, yang secara fisik ada dan dapat diamati, seperti grafik, gambar, persamaan dan tabel; (2) representasi internal, model, skema atau konsep yang mental atau kognitif dan tidak bisa dapat diamati secara langsung. Miller \& Hudson juga mengklasifikasikan representasi menjadi tiga jenis, yaitu: (1) konkrit; (2) representasional; dan (3) abstrak (H Retnawati, 2018). Klasifikasi ini mirip dengan mode representasi oleh Bruner di dalam Hebert \& Powell yaitu (1) enaktif; (2) ikonik; (3) simbolis (Powell S R, 2016). Di lain pendapat, Villages et al. (2009) menyebutkan jenis-jenis representasi eksternal yaitu: 1) representasi verbal; itu pada dasarnya diekspresikan dalam tulisan atau pidato; 2) representasi gambar; termasuk gambar, diagram atau grafik, serta beberapa kegiatan yang saling terkait; 3) representasi simbolik; terdiri dari angka, operasi dan tanda koneksi, simbol aljabar dan beberapa tindakan yang saling berhubungan (Dwi Rahmawati, 2017). Dengan demikian, melalui bentuk-bentuk representasi tersebut, maka dapat menjadi suatu cara dalam menyelesaikan masalah matematika dalam pembelajaran matematika. Strategi pemecahan masalah heuristik merupakan salah satu strategi yang digunakan untuk merepresentasikan sebuah masalah matematika. Heuristik adalah suatu langkah-langkah umum yang memulai memecahkan masalah dalam menemukan solusi masalah (Dindin Abdul Muiz Lidinillah, 2011). 
Menurut Schoenfeld (1980) bahwa:

"Heuristic will be used here to mean a general suggestion or strategy, independent of any particular topic or subject metter, that helps problem solver approach and understand a problem and efficiently marshal their resources to solve it." (Scoenfeld, Alan H., 1980)

Menurut pengertian heuristik berdasarkan pendapat Schoenfeld di atas, heuristik dapat disebut sebagai strategi umum yang tidak berhubungan dengan subjek materi, dapat membantu memecahkan masalah dalam upaya memahami masalah dan menggunakan kemampuannya untuk menemukan solusi dari masalah tersebut. Penggunaan istilah heuristik dalam pemecahan masalah berbeda dengan algoritma yang terdapat dalam pembelajaran matematika. Algoritma adalah metode yang selalu menghasilkan solusi dari suatu masalah, cepat atau lambat (Dindin Abdul Muiz Lidinillah, 2011), namun algoritma itu seringkali tidak efisien dan tidak canggih. Mathlin mengatakan bahwa metode lain yang lebih canggih, dapat mempersempit ruang eksplorasi untuk memperoleh solusi. Orang yang memecahkan masalah itu akan menerapkan informasi yang relevan mengenai permasalahan dalam upaya untuk mempersempit ruang permasalahan. Misalkan untuk menyelesaikan anagram yang panjang, maka kita bisa mengambil kombinasi inisial dari setiap huruf. Strategi dengan hanya mencari kombinasi huruf yang bisa diucapkan inilah yang dinamakan dengan heuristik. Heuristik merupakan aturan yang meliputi pencarian yang selektif yang hanya tertuju kepada ruang permasalahan guna menghasilkan solusi (Mathlin, Margareth W., 1994). Jika algoritma adalah suatu kemampuan khusus sementara heuristik merupakan pendekatan secara umum dalam pemecahan masalah. Heuristik sangat dekat dengan pengertian penemuan.

Dalam pembelajaran matematika, seringkali kita jumpai peserta didik diberikan permasalahan matematika berupa soal/situasi matematika, lalu mereka berusaha menyelesaikannya. Ada yang dapat menentukan jawaban dengan cepat dan ada juga yang membutuhkan waktu yang cukup lama, ada yang menyelesaikan permasalahan tersebut dengan menyebutkan hasil akhir secara langsung dan ada juga yang 
menyelesaikannya melalui serangkaian tahap berpikir. Bagi peserta didik yang menggunakan serangkaian tahap berpikir, perlu untuk memikirkan langkah-langkah atau strategi apa yang akan digunakan dalam menyelesaikan soal tersebut. Sedangkan bagi peserta didik yang menentukan teknik penyelesaian dengan cepat tanpa proses itu biasanya menggunakan teknik yang biasa digunakan. Mathematics is one of the sciences that must be studied by the students (Bella Wicasari, 2017) and mathematics is a logically organized conceptual system (Juan D. Godino, 2015). Ini berarti bahwa matematika merupakan ilmu yang wajib dipelajari oleh peserta didik dan matematika memuat konsep-konsep yang diatur secara logis. Dindin (2011) juga mengemukakan bahwa matematika itu memuat konsep dan aturan yang ditemukan melalui serangkaian penemuan dan pembuktian. Disinilah peran heuristik dalam pembelajaran matematika yaitu menuntun atau memandu peserta didik untuk menemukan konsep dan aturan dalam matematika hingga menemukan solusi dari permasalahan matematika tersebut. Kajian tentang pemecahan masalah dalam pembelajaran matematika tentunya tidak dapat lepas dari strategi pemecahan masalah agar dapat melatih cara berpikir peserta didik melalui langkah-langkah penyelesaian yang kemudian direpresentasikan dengan berbagai cara. Pentingnya kajian mengenai strategi pemecahan masalah heuristik ini sebagai salah satu metode untuk merepresentasikan permasalahan matematika peserta didik dalam pembelajaran matematika, maka penulis lakukan kajian lebih lanjut.

\section{METODE PENELITIAN}

Tulisan ini menggunakan kajian studi pustaka yang merupakan telaah dari literatur buku Mathlin. Metode yang digunakan untuk teknik pengumpulan data dengan mengadakan studi penelahaan terhadap literatur Mathlin yang terkait dengan bagaimana strategi pemecahan masalah heuristik dan representasi matematis, yang kemudian dilengkapi dengan catatan-catatan, dan laporan-laporan yang ada hubungannya dengan masalah yang dipecahkan tersebut. Setelah dianalisis, dilakukan penarikan kesimpulan terhadap kajian tersebut. 


\section{HASIL PENELITIAN DAN PEMBAHASAN}

Gersten (2009) memberikan pendapat tentang contoh heuristik dalam pembelajaran matematika yaitu menggunakan ekspresi aljabar, operasi hitung, dan pemikiran yang logis dalam penyelesaian masalahnya. Sedangkan penggunaan kalkulator tidak dianggap sebagai heuristik.

At its most basic, a heuristic is "a short cut in problem solving; it is a rule for reducing the number of mental operations (or information-processing steps) taken to solve a problem" (Gray, P., 1994). Sometimes heuristics are taught by teachers, sometimes students come across them on their own. It is important to note that heuristics are general strategies that a student can use on their own to help identify and solve a math problem (Gersten, R., Chard, D. J., Jayanthi, M., Morphy, P., \& Flojo, J., 2009).

Lebih lanjut dijelaskan bahwa terkadang heuristik diajarkan oleh guru dan terkadang peserta didik sendiri yang menemukannya. Penting untuk dicatat bahwa heuristik adalah strategi umum yang dapat digunakan oleh peserta didik sendiri untuk membantu mengidentifikasi dan memecahkan masalah matematika (Gersten, R., Chard, DJ, Jayanthi, M., Morphy, P., \& Flojo, J ., 2009).

Heuristik merupakan strategi yang digunakan untuk menemukan dan memecahkan suatu masalah matematika dengan menggunakan langkah-langkah penyelesaian. Heuristik banyak digunakan dalam bidang inteligensia buatan dan didefinisikan sebagai petunjuk praktis yang dapat memperpendek proses pencarian untuk menemukan penyelesaian masalah (Charniak, Eugene and Drew McDermot, 1987). Penyelesaian masalah dalam bidang inteligensia buatan didominasi oleh proses pencarian (searching). Bila pencarian dilakukan secara linier maka akan sangat banyak menghabiskan waktu karena masalah-masalah dalam bidang inteligensia buatan memunculkan alternatif penyelesaian yang amat banyak. Metode heuristik digunakan untuk menggantikan metode linier karena metode heuristik memberi peluang untuk melompati beberapa langkah atau menebak langkah penyelesaian yang lebih pendek agar pemecahan masalah lebih cepat ditemukan. Prinsip heuristik dibangun 
berdasarkan fakta dan hubungan (Gabringer, R.Scott, David Jonassen and Brent G. Wilson, 1992). Pengetahuan dan pengalaman pelaku pemecahan masalah sangat mendukung penguasaan fakta dan hubungan. Apabila sejumlah prinsip heuristik sudah dipelajari maka pelaku bisa melompatlompat sehingga akan menyederhanakan masalah dan memperkecil waktu kerja. Oleh karena itu heuristik juga dipandang sebagai alat kognitif, model kognitif informal atau petunjuk praktis yang dapat digunakan untuk mengubah pemecahan masalah yang kompleks menjadi operasi pengambilan keputusan yang sederhana

Berikut beberapa heuristik dasar (generik) dalam matematika, yaitu: 1) search for pattern; 2) drawn a figure; 3) formulate an equivalent problem; 4) modify the problem; 5) choose effective notation; 6) exploit symmetry; 7) divide into cases; 8) work backward; 9) argue by contradiction; 10) check for parity; 11) consider extreme case; and 12) generalize. Masih banyak heuristik dasar dalam matematika seperti: simplication, ambiguity, contrarian view, dan extrem focus (Sickafus, Ed., 2004). Heuristik juga digunakan dalam berbagai bidang terapan matematika seperti dalam teori graph yang memodelkan transportasi, heuristik digunakan untuk menentukan lintasan paling efisien jika setiap lintasan antar kota diberi robot dengan waktu dan biaya (Dindin Abdul Muiz Lidinillah, 2011).

Sedangkan Mathlin (1994) mengemukakan dalam bukunya yang berjudul Kognitif bahwa heuristik itu ada 3 (tiga) jenis yaitu: the analogy approach, The Means-Ends Heuristic, and The Hill-Climbing Heuristic. Sedangkan dalam penelitian Novotna, et al melaporkan bahwa ada 6 (enam) strategi dalam heuristik yaitu 1) systematic experimentation; 2) guess-check-revise; 3) working backwards; 4)introduction of an auxiliary element; 5) specification and generalization; and 6) analogy (Petr Eisenmann2 \& Jarmila Novotná \& Jiří Přibyl \& \& Jiří Břehovský, 2015). Adapun dalam tulisan ini akan dibahas heuristik berdasarkan pendapat Mathlin. 


\section{The Analogy Approach}

Setiap hari kita menggunakan analogi untuk menyelesaikan masalah. Untuk menyelesaikan masalah matematika, kita akan menggunakan caracara sebelumnya. Misalnya, dalam kuliah statistik, untuk dapat mengerjakan soal-soal statistik, maka kita dapat menggunakan contohcontoh yang ada di dalam buku ajar. Contoh lainnya adalah ketika menulis makalah tentang psikologi kognitif, maka kita akan banyak mengingat-ingat kembali dan bahkan menggunakan bahan ajar sebelumnya untuk menyelesaikannya. Saat kita menggunakan pendekatan analogi dalam pemecahan masalah, maka kita juga menggunakan solusi yang mirip dengan solusi masalah yang akan kita selesaikan (Mathlin, Margareth W., 1994). Sedangkan menurut Eisenmann et.al menjelaskan bahwa penggunaan pendekatan analogi ini juga dapat didasarkan pada fakta bahwa pemecahan suatu masalah 'analogis' dengan masalah aslinya lebih sederhana. Pemecah masalah menemukan jalan ke solusi dan kemudian menerapkan prosedur solusi untuk masalah sumber dan yang terpenting adalah bahwa pemecah masalah mengajukan masalah analogis ini sendiri. Misalnya dengan mengganti objek dalam soal dengan objek lain. Beberapa dari kualitas objek tetap utuh, yang lain berubah. Contohnya, bola diganti dengan lingkaran, angka yang lebih besar diganti dengan angka yang lebih kecil, dan $8 \times 8$ papan catur diganti dengan papan catur $3 \times 3$ (Petr Eisenmann2 \& Jarmila Novotná \& Jiř́ Přibyl \& \& Jiř́i Břehovský, 2015).

Dengan pendekatan analogi, kita juga menyelesaikan masalah target dengan menggunakan struktur penyelesaian masalah sumber yang meliputi empat komponen yaitu structuring (penataan), mapping (pemetaan), applying (menerapkan), dan verifying (memverifikasi). Structuring atau penataan merupakan salah satu komponen penting dalam berpikir analogi karena aturan pemecahan masalah dalam berpikir analogi dari domain basis ke domain target didasarkan pada pemetaan struktur. Gentner mengatakan bahwa pemetaan struktur pertama kali diperkenalkan untuk memperjelas pentingnya kesamaan struktural antara domain sumber dan domain target atau hubungan antar objek untuk setiap domain (Lailiyah et al., 2018). Jadi, dalam analogi ini dikenal istilah masalah 
sumber dan masalah target. Masih mengenai analogi ini, Lindsey mengemukakan bahwa analogi itu merupakan kemampuan untuk memahami fenomena sebagai sistem hubungan terstruktur yang dapat diselaraskan, dibandingkan, dan dipetakan bersama- sama, memainkan peran mendasar dalam teknologi iklim pendidikan yang kaya dan semakin mendunia pada abad ke-21 (Lindsey Engle Richland, n.d.). Penjelasan Lindsey mengenai analogi ini lebih mengarah kepada penalaran analogi meskipun pendekatan analogi yang dimaksud di dalam kajian ini juga merujuk kepada berpikir secara analogi. Strategi heuristik dengan analogi ini memang tidaklah mudah, membutuhkan kerja keras, ketekunan, dan percaya diri untuk dapat mengungkapkannya atau mempresentasikannya. Selain itu, orang yang memiliki keterampilan pemecahan masalah terbatas dan metakognitif terbatas kemampuan sangat mungkin mengalami kesulitan menggunakan analogi (Chen et al., 2004; Davidson \& Sternberg, 1998) (Mathlin, Margareth W., 1994).

Selanjutnya, Novick's kemudian melakukan penelitian mengenai analogi ini dan didapatkan bahwa seseorang itu seringkali mengalami kesulitan pada analogi yaitu saat mengubah pengetahuannya dari suatu masalah ke masalah lainnya. Menurut Novick's, kesulitan ini disebabkan oleh karena orang yang memecahkan masalah itu terfokus kepada gambaran permukaan yang menonjol yaitu benda-benda dan istilah yang digunakan pada pertanyaan. Novick's juga menunjukkan bahwa pemecahan masalah yang berhasil dengan menggunakan analogi, memerlukan 4 proses yang berlainan yaitu: mencari atau menempatkan problem sumber secara tepat; membuat peta, atau membangun hubungan aturan antara bagian-bagian dari problem sumber dan bagian-bagian dari problem target; adaptasi atau menentukan bagaimana menggunakan prosedur yang sama bagi problem target yang berhasil untuk menyelesaikan problem sumber; dan belajar atau menggambarkan skema abstrak untuk keseluruhan masalah yang mewakili problem sumber dan problem target. 


\section{The Means-Ends Heuristic}

Bila kita menggunakan the means-ends heuristic, maka kita akan membagi permasalahan ke dalam sejumlah sub masalah. Lalu, kita mulai menyelesaikan setiap sub masalah dengan cara memantau perbedaan antara keadaan awal dan keadaan tujuan, kemudian mengurangi perbedaan kedua keadaan tersebut.

Sebagai contoh dalam the means-end heuristic ini adalah memecahkan masalah perpindahan Peri-dan-Goblin. Ruang kerjanya menunjukkan bahwa orang berhenti pada poin-poin dalam masalah ketika mereka mulai menangani sub masalah dan perlu mengatur urutan bergerak. Dalam strategi ini, solusi yang tepat untuk menyelesaikan masalah adalah bergerak mundur, meningkatkan sementara perbedaan antara keadaan awal dan keadaan tujuan. Di dalam permasalahan Peri dan Goblin tersebut, terdapat 11 kali perpindahan Peri dan Goblin dari keadaan awal menuju keadaan tujuan atau sebaliknya.

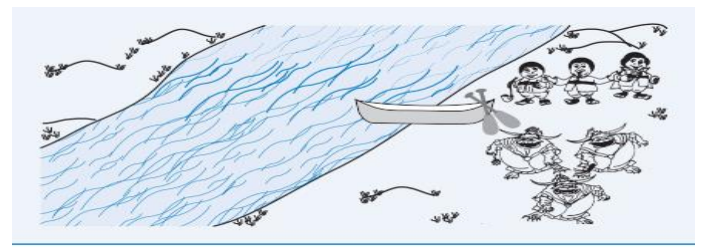

\section{Gambar 1. Ilustrasi Masalah Perpindahan Peri dan Goblin (Mathlin, Margareth W., 1994)}

Kita dapat menemukan contoh lainnya dari strategi the means-end heuristic dalam pembelajaran matematika, misalnya dalam menyelesaikan soal cerita tentang persamaan linear dengan menggunakan sistem eliminasi yaitu menentukan umur si A dan si B jika diberikan perbandingan usia mereka menggunakan selisih tahun atau kelipatan tahun kelahiran.

Dengan demikian, The Means-Ends Heuristic ini membagi masalah menjadi sub masalah dan lalu mencoba mengurangi perbedaan antara keadaan awal dan keadaan tujuan untuk masing-masing sub masalah. Dalam kasus-kasus tertentu, Means-Ends analysis mungkin saja bukan 
pendekatan yang terbaik. Terkadang solusi suatu masalah ditentukan oleh pertambahan perbedaan sementara antara keadaan awal dan keadaan tujuan.

\section{The Hill-Climbing Heuristic}

Pendekatan pendakian bukit dikenal juga dengan sebutan pendekatan pandakian bukit (Charniak, Eugene and Drew McDermot, 1987). Dalam pendakian bukit seseorang berusaha mencapai puncak pertama, kemudian puncak berikutnya yang terdekat, dan seterusnya sampai mencapai puncak yang tertinggi. Dalam pemecahan masalah proses diawali dengan menyelesaikan sub-masalah terdekat, kemudian menuju sub-masalah berikutnya yang terdekat. Begitu seterusnya sampai tidak ada lagi sub-masalah yang belum terpecahkan, yang berarti masalah secara keseluruhan sudah terselesaikan (I Made Candiasa, 2017). Untuk dapat lebih memahami mengenai pendekatan ini, simak baik-baik ilustrasi berikut:

Bayangkan Anda sedang mendaki di sepanjang jalan masuk daerah yang tidak dikenal. Tujuan Anda adalah mencapai puncak bukit. Di depan, Anda melihat sebuah percabangan di jalan ini. Sayangnya, Anda tidak dapat melihat jauh ke kejauhan pada salah satu dari keduanya jalur. Karena tujuan Anda adalah mendaki ke atas, Anda pilih jalur yang paling curam lereng. Demikian pula, jika Anda menggunakan heuristik panjat bukit — dan Anda mencapai titik pilihan — Anda secara konsisten memilih alternatif yang tampaknya paling langsung memimpin menuju tujuan Anda (Lovett, 2002; Ward \& Morris, 2005) (Mathlin, Margareth W., 1994). Maka, kemudian pendekatan mendaki bukit ini tidak menjadi pilihan terbaik dalam memecahkan masalah sebab pendekatan ini hanya mendorong tujuan jangka pendek, bukan solusi jangka panjang seperti yang diilustrasikan pada contoh sebelumnya yaitu untuk sampai ke puncak bukit, kita harus konsisten dengan jalan yang kita pilih, bukan menggunakan jalan lain (alternative) yang belum tentu membawa kita menuju bukit tersebut. Jika kita menggunakan jalan lain, maka kemungkinan yang akan terjadi adalah kita sesat dan kita gagal sampai ke bukit. 
Dalam pembelajaran matematika, pendekatan ini dapat kita jumpai saat kita menyelesaikan soal matematika seperti menyelesaikan soal-soal aljabar yang dapat menggunakan berbagai cara alternatif.

Pembelajaran matematika dengan menggunakan strategi heuristik ini dapat dilakukan secara indvidu atau pun kelompok. Akan tetapi sebaiknya dilakukan secara berkelompok dengan kelompok-kelompok kecil agar dapat bertukar pikiran satu sama lain dalam menemukan solusi masalah sebab strategi pemecahan masalah heuristik ini merupakan strategi yang cukup sulit untuk dilaksanakan namun memiliki banyak manfaat bagi pola pikir peserta didik dan dapat meningkatkan kreativitas peserta didik melalui ide-ide solusi yang dituangkan peserta didik dalam menemukan dan menyelesaikan masalah. Representasi merupakan bagian dari ungkapan ide-ide peserta didik tersebut yang dapat dilakukan oleh peserta didik dengan berbagai bentuk yaitu mengungkapkan dengan katakata atau verbal, simbol-simbol, menggunakan persamaan matematika dan menampilkan gambar atau visual. Berdasarkan teori, representasi dapat membantu menyelesaikan masalah dan sebaliknya sehingga terdapat hubungan sebab akibat di antara keduanya. Masalah matematika akan lebih mudah dapat diselesaikan jika peserta didik mampu merepresentasikannya melalui berbagai macam bentuk dan salah satunya adalah dengan strategi heuristik yang merupakan salah satu metode untuk merepresentasikan masalah-masalah matematika dalam pembelajaran matematika baik dengan menggunakan analogy, the means-ends heuristic, maupun the hill-climbing.

\section{SIMPULAN}

Masalah merupakan suatu situasi dimana seseorang tersebut mampu menyadari keberadaan situasi dan mengakui bahwa situasi tersebut memerlukan tindakan dan penyelesaian yang tidak mudah. Masalah dalam matematika biasanya dalam bentuk pertanyaan atau soal. Dalam matematika terdapat dua kriteria pertanyaan atau soal yaitu bersifat menantang dan menuntut prosedur yang tidak rutin dalam penyelesaiannya. Dalam pembelajaran matematika, seringkali kita jumpai peserta didik diberikan permasalahan matematika berupa soal/situasi 
matematika, lalu mereka berusaha menyelesaikannya. Ada yang dapat menentukan jawaban dengan cepat dan ada juga yang membutuhkan waktu yang cukup lama, ada yang menyelesaikan permasalahan tersebut dengan menyebutkan hasil akhir secara langsung dan ada juga yang menyelesaikannya melalui serangkaian tahap berpikir. Dengan menggunakan strategi pemecahan masalah maka peserta didik kemudian dapat melakukan representasi matematis terhadap masalah tersebut yang merupakan salah satu kemampuan dalam matematika yang berkaitan dengan pemecahan masalah, penalaran, pembuktian, dan komunikasi. Representasi masalah mengacu pada cara menerjemahkan elemen masalah ke dalam format yang berbeda. Antara strategi dan representasi memiliki dua arah dimana strategi dapat mempengaruhi representasi dari masalah, terdapat efek kausal dari penggunaan strategi ini. Mathlin (1994) mengemukakan dalam bukunya yang berjudul Kognitif bahwa heuristik itu ada 3 (tiga) jenis yaitu: the analogy approach, the means-ends heuristic, and the hill-climbing heuristic. Heuristik dapat disebut sebagai strategi umum yang tidak berhubungan dengan subjek materi, dapat membantu memecahkan masalah dalam upaya memahami masalah dan menggunakan kemampuannya untuk menemukan solusi dari masalah tersebut. Metode heuristik digunakan untuk menggantikan metode linier karena metode heuristik memberi peluang untuk melompati beberapa langkah atau menebak langkah penyelesaian yang lebih pendek agar pemecahan masalah lebih cepat ditemukan.

\section{DAFTAR PUSTAKA}

A. F. Samsuddin, H. Retnawati. (2018). IOP Conf Ser. J. Phys. Conf Ser., 1097 (012152).

Bella Wicasari, Z. E. (2017). 45-57.

Charniak, Eugene and Drew McDermot. (1987). Artificial Intelligence, Reading. Massachusetts: Addison Wesley Publishing Company.

Dindin Abdul Muiz Lidinillah. (2011). Heuristik dalam Pemecahan Masalah Matematika dan Pembelajarannya di Sekolah Dasar. Jurnal Elektronik. 
Dwi Rahmawati, R. B. A. (2017). International Education Studies, 10(10).

Gabringer, R. Scott, David Jonassen and Brent G. Wilson. (1992). "The Use of Expert System," Handbook of Human Performance Problems in Organization, ed. Harold D. Stolovich \& Erica J. Kepps. San Francisco: Joseey-Bass Publishers.

Gersten, R., Chard, D. J., Jayanthi, M., Morphy, P., \& Flojo, J. (2009). Mathematics instruction for students with learning disabilities: A meta-analysis of instructional components. Review of Educational Research. 79, 1202-1242.

Gray, P. (1994). Psychology (2nd ed.). New York, NY: Worth Publishers. H Retnawati, A. F. S. (2018). IOP Conf. Series: Journal of Physics: Conf. Series, 1097(012152).

I Made Candiasa. (2017). Strategi Heuristik untuk Meningkatkan Ketahanmalangan Peserta didik dalam Pembelajaran Matematika. SEMINAR NASIONAL RISET INOVATIF.

James A. Dixon, R. B. (2009). Strategies and problem representations: Implications for models of changing cognitive structure. Commentary on "Learning new problem-solving strategies leads to changes in problem representation" by M.W. Alibali, K.M. Ockuly and A.D. Fischer. 24, 102-105. https://doi.org/10.1016/j.cogdev.2009.03.002

Juan D. Godino. (2015). Mathematical Concepts, Their Meanings, and Understanding. https://www.researchgate.net/publication/253279297 Juniati, N. I. (2018). Kemampuan Representasi Matematis Peserta didik dalam Menyelesaikan Soal Cerita Materi Program Linear di $\begin{array}{llll}\text { Madrasah } & \text { Aliyah Negeri } 2 & \text { Pontianak. }\end{array}$ Jurnal.Untan.ac.id/Index.Php/Jpdpb/Article/Download/28988/75676 578727.

Lailiyah, S., Nusantara, T., Sa'dijah, C., Irawan, E. B., Kusaeri, \& Ashar, A. H. (2018). Structuring Students' Analogical Reasoning in Solving Algebra Problem. IOP Conf. Series: Materials Science and Engineering 296 (2018) 012029, 1 - 6. Doi: 10.1088/1757-899X/296/ $1 / 012029$. 
Lindsey Engle Richland, N. S. (n.d.). WIREs Cogn Sci 2015. Doi: 10.1002/Wcs. 1336.

Mathlin, Margareth W. (1994). Kognitif Edisi Ketiga. Terjemahan Nilawati Tadjuddin Syabri Harcourt Brace Publisher: State University of New York.

Petr Eisenmann2 \& Jarmila Novotná \& Jiří Přibyl \& \& Jiř́ Břehovský. (2015). The development of a culture of problem solving with secondary students through heuristic strategies. Math Ed Res J, 27 (535-562).

Powell S R, H. M. A. (2016). 29(7), 1511-1537.

Scoenfeld, Alan H. (1980). Heuristik in the Classroom, dalam Krulik, S. dan Reys, Robert E. (Eds). Problem Solving in School Mathematic. NCTM.

Sickafus, Ed. (2004). Heuristics for Solving Technical Problem: Theory, Derivation, Application.

Wahyudi, I. A. (2017). Strategi Pemecahan Masalah Matematika. Satya Wacana University Press.

Wardono, F., S. D. (2019). Representasi Matematika dalam Pemecahan Masalah. PRISMA, Prosiding Seminar Nasional Matematika, 606610. 